\title{
КОМПЛЕКСНЫЙ АНАЛИЗ СДВИГОВ В СТРУКТУРЕ ИНВЕСТИЦИЙ ДАЛЬНЕВОСТОЧНОГО РЕГИОНА *
}

\section{(c) 2020 Олейник Елена Борисовна}

доктор экономических наук, доцент, профессор кафедры

Дальневосточный федеральный университет, Россия, Владивосток

E-mail: oleynik.eb@dvfu.ru

\section{(c) 2020 Захарова Алена Петровна}

кандидат экономических наук, доцент, доцент кафедры

Дальневосточный федеральный университет, Россия, Владивосток

E-mail: zakharova.ap@dvfu.ru

\section{(c) 2020 Юрченко Елена Григорьевна}

кандидат физико-математических наук, доцент, доцент кафедры Дальневосточный федеральный университет, Россия, Владивосток

E-mail: yurchenko.eg@dvfu.ru

Рассмотрена структура и динамика объемов промышленного производства и структура инвестиций в Дальневосточном федеральном округе. Определены основные направления инвестиций и представлены основные инвестиционные проекты региона. Проведен расчет и анализ интегральных сдвигов в структуре инвестиций. Сделан вывод о тенденциях реализации инвестиционной политики и инвестиционного климата региона.

Ключевые слова: инвестиции, инфраструктурные проекты, интегральный коэффициент, структурные сдвиги

Дальневосточный федеральный округ (ДВФО) - важная геостратегическая территория России. Ведущей отраслью на Дальнем Востоке является промышленность. Устойчивое развитие промышленности в регионе началось с 2002 года (рис. 1). Темп роста объемов промышленного производства в регионе, начиная с 2010 г. опе- режал соответствующие показатели по России. За период 2015-2019 гг. прирост промышленного производства в ДВФО составил 23\%, тогда как по России - 8,3\%. В северных субъектах макрорегиона доля промышленного производства в структуре экономики выше в связи с ориентацией на добычу редких и уникальных видов сы-

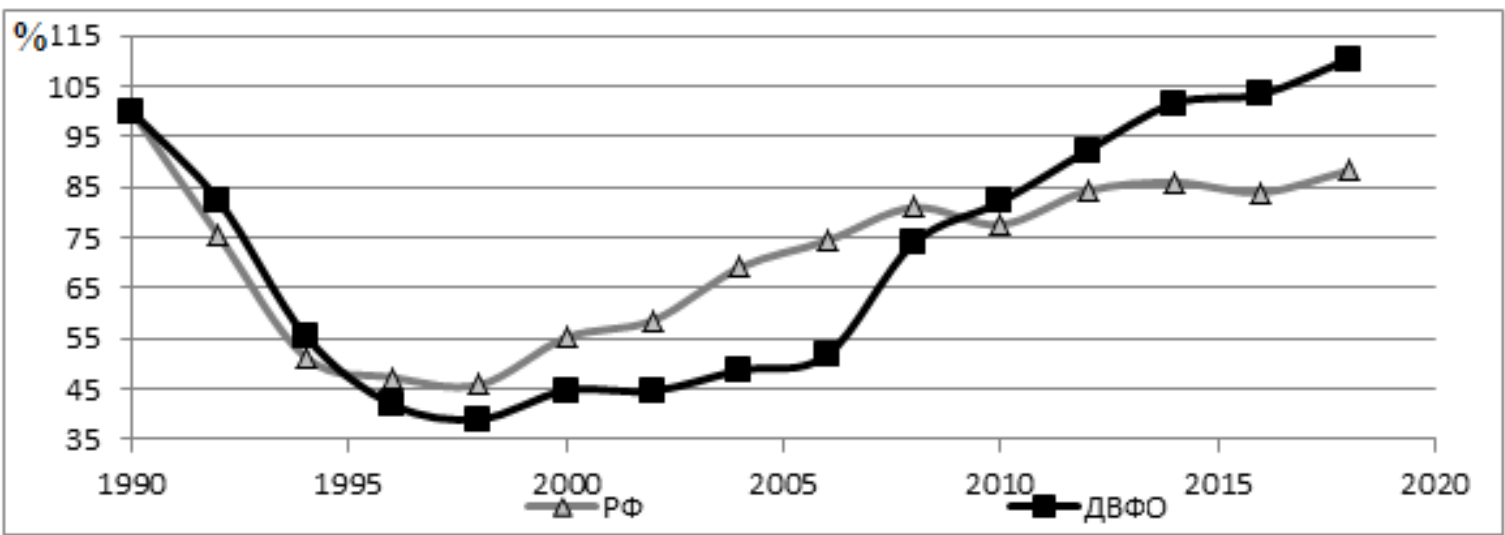

Puc. 1. Динамика промышленного производства в России и ДВФО, в \% к 1990 году

\footnotetext{
* Работа подготовлена в рамках гранта РФФИ № 19-010-00085 «Комплексная оценка структурной динамики экономической системы Дальневосточного региона на основе моделирования результатов стратегических инвестиционных проектов»
} 
рья. Южные районы в составе промышленности имеют более широкую номенклатуру предприятий, в том числе перерабатывающего профиля. Главным источников роста ВРП остается добыча нефти, газа и природных ресурсов. Валовой выпуск добывающей отрасли в 2017 году составил 1,1 трлн. руб., или 26,1\% ВРП округа.

Сопоставимы с ней лишь сферы транспорта и торговли: они формируют $12,7 \%$ и $10,9 \%$ ВРП соответственно, а на каждую из других отраслей приходится меньше 8\%. По данным [1] в 2018 г. в структуре промышленности наибольший удельный вес отгруженной продукции приходится на добычу полезных ископаемых - 67\%, а на обрабатывающие производства всего лишь 20,2\%.

По данными $[1,5]$ лидерами по уровню экономического развития в ДВФО являются республика Бурятия, республика Саха (Якутия) и Магаданская область, у которой наблюдается минимальный индекс физического объема инвестиций в основной капитал $-47,9$ (рис. 2) и максимальный индекс промышленного производства - 114,2. Следовательно, важен не только и не столько прирост инвестиций, а то, как они распределяются. Наблюдаемая за последние три года позитивная динамика прироста объемов инвестиций является следствием включения в состав ДВФО Бурятии и Забайкальского края, чьи инвестиции в отрасль суммарно составили 10 млрд. руб. (или $11 \%$ от вложений округа).

По данным [5] в структуре экспорта ДВФО преобладают сырьевые товары - 10,8 млрд. долларов США (74,4\% от общего объема экспорта), что составляет 10,7\% экспорта сырья РФ. Основ- ными субъектами-экспортерами, на которые приходится 73,3\% вывозимого сырья, являются Сахалинская область, Республика Саха (Якутия) 8,1 и 2,1 млрд. долларов США, соответственно.

Значительное преобладание сырья в структуре экспорта и добывающей промышленности в структуре промышленного производства явно указывают на серьезные проблемы в экономике региона. Выделим основные из них: исчерпание и снижение эффективности использования природных ресурсов, значительный и постоянный отток населения из региона, трудности адаптации к распространению новых «прорывных» технологий. Совокупность проблем их сложность и масштаб таковы, что они не могут быть решены или устранены исключительно за счет увеличения использования внутренних ресурсов региона. Для решения этих проблем привлекаются значительные инвестиции, но главное в том, в какую отрасль они направляются и как распределяются между проектами. В нашей работе [10] были выявлены основные направления инвестиций, которые могли бы привести к сдвигам в структуре экономики ДВФО, это, в первую очередь, инфраструктурные проекты, инвестиции в обрабатывающие производства и инвестиции в развитие социальной сферы.

Особенности некоторых регионов (большие площади, суровый климат, крайне низкая плотность населения) предполагает основное направление потоков инвестиций на реализацию проектов по созданию и развитию инфраструктуры: социальной (школы, садики, центры здравоохранения), энергетической и инженерной

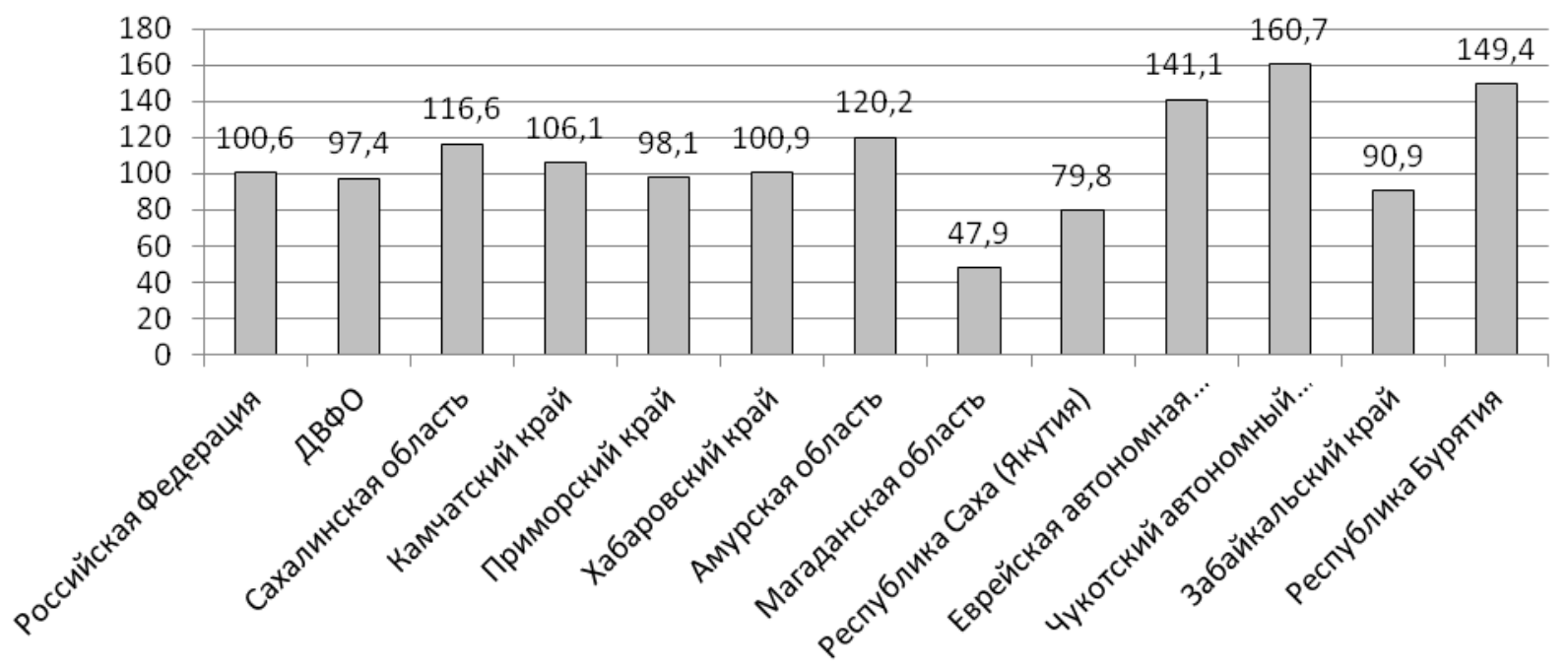

Puc. 2. Индекс физического объема инвестиций в основной капитал за 2019 г. регионов ДВФО и Российской Федерации, в\% к 2018 г. 
(инженерные сети и коммуникации).

По данным [1,5,7] расходы бюджетов регионов Дальнего Востока на инфраструктуру в 2018 году выросли в номинальном выражении впервые за три года - до 93,4 млрд. руб., или почти на $11 \%$ к прошлому году. Их доля в ВРП округа, напротив, сократилась до 1,99\% с 2,2\% в 2017-м. На инвестиции в инфраструктуру региона пришлось 7\% вложений бюджетов всех регионов страны. Частные инвесторы направили на реализацию инфраструктурных проектов 280-400 млрд. руб. Однако, это по-прежнему сравнительно небольшие расходы: например, в Сибирском и Уральском округах вложения составляли до 470 млрд. руб. и 730 млрд. руб. соответственно. Перспективы дальнейшего роста иностранных инвестиций на Дальнем Востоке зависят, прежде всего, от снижения инвестиционных рисков, к которым относятся слаборазвитая транспортная инфраструктура, проблемы сбыта готовой продукции в таком малозаселенном регионе, длительные бюрократические процедуры.

Инфраструктурные проекты, как самые дорогостоящие, развиваются при поддержке государственных институтов, а кредитование является наиболее распространенным способом финансирования проектов в форме государственночастного партнерства. В 2015 г. в Дальневосточном федеральном округе был запущен новый механизм - предоставление инвесторам за счет федерального бюджета субсидий на компенсацию части затрат на создание и (или) реконструкцию объектов инфраструктуры, а также на технологическое присоединение к электрическим и газораспределительным сетям в целях реализации инвестиционных проектов. Размер субсидий из федерального бюджета на финансирование части затрат на инфраструктуру, необходимую для реализации проекта, напрямую зависит от размера частных инвестиций. Наиболее крупные совместные инвестиционные проекты, реализуемы в ДВФО, представлены в табл. 1.

В банковском секторе сконцентрирована наибольшая часть средств, которые могут быть инвестированы в экономику Дальневосточного региона. Наиболее активными кредиторами являются крупнейшие госбанки (Сбербанк, группа ВТБ и Газпромбанк). Однако в ДВФО их привлекают капиталоемкие проекты от 5 млрд. руб. (табл. 2), поэтому без внимания инвесторов остается большая часть проектов социальной сферы. Однако при всей своей привлекательности крупные проекты обладают свойством локализации. Отдаленность локализованного размещения создает преграды для привлечения дополнительных ресурсов. Вследствие этого социальный эффект от таких проектов оказывается ограниченным, несмотря на увеличение налоговых поступлений, числа созданных рабочих мест и уровня деловой активности.

Таблица 1. Основные инвестиционные проекты, реализуемые в ДВФО

\begin{tabular}{|l|l|c|c|}
\hline \multicolumn{1}{|c|}{ Проект } & \multicolumn{1}{|c|}{ Территория } & $\begin{array}{c}\text { Частные } \\
\text { инвестици, } \\
\text { млрд. руб. }\end{array}$ & $\begin{array}{c}\text { Бюджетные } \\
\text { субсидии, } \\
\text { млрд. руб. }\end{array}$ \\
\hline Горно-обогатительный комплекс «Инаглинский» & $\begin{array}{l}\text { Республика Саха } \\
\text { (Якутия) }\end{array}$ & 23,9 & 0,6 \\
\hline $\begin{array}{l}\text { Транспортно- перегрузочный комплекс в порту } \\
\text { Ванино }\end{array}$ & Хабаровский край & 19,6 & 3,3 \\
\hline Проект развития угледобычи и углеобогащения & Хабаровский край & 23,7 & 1,5 \\
\hline Развитие золотодобычи в Селемджинском районе & Амурская область & 36,5 & 5,5 \\
\hline Горно-металлургический комбинат & Камчатский край & 12,2 & 0,8 \\
\hline $\begin{array}{l}\text { 1-я очередь Таежного горно-обогатительного } \\
\text { комбината }\end{array}$ & $\begin{array}{l}\text { Республика Саха } \\
\text { (Якутия) }\end{array}$ & 12,2 & 1,6 \\
\hline Наталкинское золоторудное месторождение & Магаданская область & 88,6 & 9,9 \\
\hline $\begin{array}{l}\text { Алмазодобывающее предприятие на базе } \\
\text { Верхне-Мунского рудного поля }\end{array}$ & $\begin{array}{l}\text { Республика Саха } \\
\text { (Якутия) }\end{array}$ & 54,5 & 8,5 \\
\hline $\begin{array}{l}\text { Строительство и эксплуатация горно- } \\
\text { обогатительного комбината «Тарын» } \\
\text { на месторождении «Дражное» }\end{array}$ & $\begin{array}{l}\text { Республика Саха } \\
\text { (Якутия) }\end{array}$ & 8,8 & 1,0 \\
\hline $\begin{array}{l}\text { Организация производства строганых и профили- } \\
\text { рованных пиломатериалов в пос. «Березовый» }\end{array}$ & Хабаровский край & 7,6 & \\
\hline
\end{tabular}

Источник: [8] 
Таблица 2. Банковские кредиты в ДВФо, 2018 г.

\begin{tabular}{|l|c|c|}
\hline \multicolumn{1}{|c|}{ Направления инвестирования } & Сумма, млрд. руб. & Доля, \% \\
\hline Оптовая и розничная торговля & 242,3 & 27,3 \\
\hline Обрабатывающие производства & 123,6 & 13,9 \\
\hline Производство и распределение электроэнергии, газа и воды & 92,3 & 10,4 \\
\hline Добыча полезных ископаемых & 66,9 & 7,5 \\
\hline Строительство & 48,3 & 5,4 \\
\hline Транспорт и связь & 33,8 & 3,8 \\
\hline Сельское хозяйство, охота и лесное хозяйство & 22,0 & 2,5 \\
\hline Прочее & 259,7 & 29,2 \\
\hline
\end{tabular}

Источник: [2,6]

Для анализа изменения структуры и эффективности инвестиционной политики используется оценка структурных сдвигов. Структурные сдвиги - изменение пропорций экономической системы под воздействием внешних факторов: экономических, природно-климатических, которые приводят к новому качеству системы. Подробный анализ подходов к оценке структурных сдвигов сделан нами в работе [9]. Поэтому в данной статье рассмотрим только те показатели, которые будем использовать для анализа структуры инвестиций.

Для оценки существенности структурных сдвигов используются различные интегральные коэффициенты. Существует несколько интегральных коэффициентов структурных различий коэффициент Гатева $\left(\mathrm{I}_{\mathrm{G}}\right)$, индекс Салаи $\left(\mathrm{I}_{\mathrm{S}}\right)$, индекс Рябцева $\left(\mathrm{I}_{\mathrm{R}}\right)$ :

$$
\begin{gathered}
I_{G}=\sqrt{\frac{\sum_{j=1}^{n}\left(f_{j}^{l}-f_{j}^{l-1}\right)^{2}}{\sum_{j=1}^{n}\left(f_{j}^{l}\right)^{2}+\sum_{j=1}^{n}\left(f_{j}^{l-1}\right)^{2}}} \\
I_{S}=\sqrt{\frac{\sum_{j=1}^{n} \frac{\left(f_{j}^{l}-f_{j}^{l-1}\right)^{2}}{\left(f_{j}^{l}+f_{j}^{l-1}\right)^{2}}}{n}} \\
I_{R}=\sqrt{\frac{\sum_{j=1}^{n}\left(f_{j}^{l}-f_{j}^{l-1}\right)^{2}}{\sum_{j=1}^{n}\left(f_{j}^{l}+f_{j}^{l-1}\right)^{2}}}
\end{gathered}
$$

где $f_{j}^{l}-$ удельный вес $j$-го элемента структуры в периоде $l, f_{j}^{l-1}$ - удельный вес $j$-го элемента структуры в периоде $l-1, n-$ число элементов структуры.

Интегральный коэффициент Гатева учи- тывает степень различий долей по отдельным группам и удельный вес сопоставляемой пары групп в двух сравниваемых структурах. Недостатком данного коэффициента является отсутствие реального содержательного смысла знаменателя [4].

Индекс Салаи в дополнение к свойствам интегрального коэффициента Гатева учитывает общее количество выделенных категорий, т.е. интегральный коэффициент Салаи является более чувствительным к структурным сдвигам в распределениях. Недостатком коэффициента является зависимость его величины от числа выделенных градаций и завышение структурных изменений [4]. Минимальные значения для коэффициентов Гатева и Салаи - 0 (случай отсутствия структурных различий). При равном количестве элементов в структурах максимальное значение данных коэффициентов не превышает 1. Если количество элементов в сравниваемых структурах различно, то коэффициенты Гатева и Салаи принимают значения больше 1, что означает неоспоримую существенность структурных различий [4]. Интегральный коэффициент Рябцева определяется как отношение фактической меры расхождений значений компонентов двух структур к их максимально возможным значениям. Предпочтительным является индекс Рябцева, имеющий шкалу оценки меры существенности различия структур (таблица 3), независящий от числа элементов структуры и не завышающий структурные изменения, как индекс Салаи [3].

Проведем расчет изменений в структуре инвестиций в основной капитал за период 20002017 гг. (таблица 4).

Как видно из приведенных в таблице 4 расчетов, все показатели структурных сдвигов за исследуемый период отражают низкий уро- 
Таблица 3. Шкала оценки меры существенности различий по индексу Рябцева

\begin{tabular}{|c|l|}
\hline Интервал значений $\mathrm{I}_{\mathrm{R}}$ & \multicolumn{1}{|c|}{ Характеристика меры структурных различий } \\
\hline $0,000-0,030$ & Тождественность структур \\
\hline $0,031-0,070$ & Весьма низкий уровень различия структур \\
\hline $0,071-0,150$ & Низкий уровень различия структур \\
\hline $0,151-0,300$ & Существенный уровень различия структур \\
\hline $0,301-0,500$ & Значительный уровень различия структур \\
\hline $0,501-0,700$ & Весьма значительный уровень различия структур \\
\hline $0,701-0,900$ & Противоположный тип структур \\
\hline $0,901-1,000$ & Полная противоположность структур \\
\hline
\end{tabular}

Таблица 4. Расчет показателей качественных изменений в структуре инвестиций в основной капитал по Дальневосточному федеральному округу за период 2000-2017 гг.

\begin{tabular}{|c|c|c|c|c|}
\hline \multirow{2}{*}{$\begin{array}{c}\text { Период } \\
\text { времени }\end{array}$} & \multirow{2}{*}{ Индекс Салаи } & \multirow{2}{*}{ Индекс Гатева } & \multicolumn{2}{|r|}{ Индекс Рябцева } \\
\hline & & & Значение & Характеристика уровня различий структур \\
\hline $2001 / 2000$ & 0,163 & 0,318 & 0,231 & Существенный уровень различий структур \\
\hline $2002 / 2001$ & 0,099 & 0,197 & 0,141 & \multirow{3}{*}{ Низкий уровень различий структур } \\
\hline $2003 / 2002$ & 0,062 & 0,124 & 0,088 & \\
\hline $2004 / 2003$ & 0,079 & 0,158 & 0,112 & \\
\hline $2005 / 2004$ & 0,168 & 0,327 & 0,238 & Существенный уровень различий структур \\
\hline $2006 / 2005$ & 0,064 & 0,127 & 0,090 & \multirow{3}{*}{ Низкий уровень различий структур } \\
\hline $2007 / 2006$ & 0,098 & 0,193 & 0,138 & \\
\hline $2008 / 2007$ & 0,102 & 0,203 & 0,145 & \\
\hline $2009 / 2008$ & 0,126 & 0,248 & 0,178 & Существенный уровень различий структур \\
\hline $2010 / 2009$ & 0,022 & 0,044 & 0,031 & Весьма низкий уровень различий структур \\
\hline $2011 / 2010$ & 0,104 & 0,207 & 0,148 & Низкий уровень различий структур \\
\hline $2012 / 2011$ & 0,031 & 0,062 & 0,044 & \multirow{2}{*}{ Весьма низкий уровень различий структур } \\
\hline $2013 / 2012$ & 0,050 & 0,100 & 0,071 & \\
\hline $2014 / 2013$ & 0,014 & 0,027 & 0,019 & Тождественность структур \\
\hline $2015 / 2014$ & 0,039 & 0,078 & 0,055 & \multirow{2}{*}{ Весьма низкий уровень различий структур } \\
\hline $2016 / 2015$ & 0,036 & 0,071 & 0,050 & \\
\hline $2017 / 2016$ & 0,069 & 0,137 & 0,098 & Низкий уровень различий структур \\
\hline
\end{tabular}

Источник: рассчитано на основании данных [5]

вень различий в структуре инвестиций в основной капитал. Существенный уровень различий структуры в 2009 г. объясняется последствиями мирового экономического кризиса 2008 г. В целом, несмотря на некоторые изменения значений интегральных индексов, структура инвестиций за 2000-2017 гг. оставалась стабильной и неэффективной. В 2018 г. доля инфраструктурных расходов в ВРП округа сократилась до 1,99\% против 2,2\% в предыдущий год [1]. В комплексном плане развития ДВФО на инфраструктурные проекты предусмотрено направить не более $3 \%$ от общего объема инвестиций.
Низкая плотность населения, суровый климат и невысокий уровень развития инфраструктуры и обрабатывающих производств сдерживают эффективные сдвиги в структуре экономики ДВФО и требует значительных объемов инвестиций в первую очередь в развитие инфраструктуры. Положительные тенденции, которые отражаются на результатах реализации инвестиционной политики и улучшении инвестиционного климата региона, подтверждается растущей динамикой инвестиционной активности в регионе. Идет процесс развития инструментов привлечения инвестиций в регион, 
введены различные дополнительные налоговые льготы и созданы благоприятные условия для реализации инвестиционных проектов, постепенно выстраивается система привлечения высококвалифицированных кадров, и создаются условия для снижения миграционного оттока населения. Однако необходимо отметить «достаточно закрытый характер информации о стадиях реализации проектов, поскольку большинство из них крайне слабо представлены в медийном пространстве» [8] и статистической отчетности, а у органов власти зачастую отсутствуют агрегированные данные по параметрам проектов, которые требуются для оценки их текущего состояния. Регион значим для развития, территориальной целостности и безопасности страны. Чтобы Дальний Восток стал стратегическим макрорегионом не только в программных документах, необходима комплексность государственной поддержки инвестиционных проектов без ожидания быстрых результатов, все это достигается как путем участия в финансировании, так и посредством разработки системных мер по созданию благоприятного инвестиционного климата в регионе.

\section{Библиографический список}

1 Барцева Г., Галактионова А., Жундриков А., Яковлевская А., Якунина Е. Инвестиции в инфраструктуру: 2018, 2019, 2020. Сборник аналитики InfraONE Research. - М.: Интеллектуальная Литература. -2020, 526c.

2 Гордеев М., Землянская Л., Лавский С., Пигалкина В. Деловой и финансовый климат Дальневосточного региона.-М.: Изд. Центр Делойт, 2018. - 40с.

3 Карелина М. Статистический анализ диверсификации интеграционной активности в экономике России // Молодой ученый. - 2013. - № 10.- С. 377-379

4 Ковалева Т. Статистические показатели в анализе структуры социальноэкономической системы // Инновационная наука. - 2015. - № 4. - С. 63-71.

5 Официальный сайт Федеральной службы государственной статистики. - URL: http://www.gks.ru (дата обращения: 10.09.2020)

6 Масакова И. и др. Инвестиции в России 2019: Стат. сб. под ред И. Масаковой.- Росстат._- М., 2019. - 228 с.

7 Фонд развития Дальнего Востока. Инвестиционные проекты. URL: https://www.fondvostok.ru/projects/ investment_projects/ (дата обращения: 12.09.2020)

8 Чичканов В., Бакланов П., Беляевская-Плотник Л., Мошков А. Реализация инвестиционных проектов с мультипликативным эффектом в регионах Дальнего Востока URL: https:/www.irpr.ru/wp-content/uploads/2019/12 (дата обращения: 09.09.2020)

9 Oleinik E., Zakharova, A. Structural approach to evaluating investments into the region economy // Indian Journal of Science and Technology. - 2016. - № 9 (12). - P. 1-9._- DOI: 10.17485/ijst/2016/v9i12/89532

10 Oleinik E., Zakharova, A. Quantitative and Qualitative Aspects of Influence of the Investments on Economic Growth// International Journal of Economics and Financial Issues. Special Issue for "Fundamental and Applied Research in Economics and Management: New Perspectives”._- 2016._ № 6(S8)._P. 340-345. 